\title{
IFIP Advances in Information and Communication Technology
}

\section{Editor-in-Chief}

A. Joe Turner, Seneca, SC, USA

\section{Editorial Board}

Foundations of Computer Science Mike Hinchey, Lero, Limerick, Ireland

Software: Theory and Practice Michael Goedicke, University of Duisburg-Essen, Germany

Education

Arthur Tatnall, Victoria University, Melbourne, Australia

Information Technology Applications

Ronald Waxman, EDA Standards Consulting, Beachwood, OH, USA

Communication Systems

Guy Leduc, Université de Liège, Belgium

System Modeling and Optimization

Jacques Henry, Université de Bordeaux, France

Information Systems

Jan Pries-Heje, Roskilde University, Denmark

ICT and Society

Jackie Phahlamohlaka, CSIR, Pretoria, South Africa

Computer Systems Technology

Paolo Prinetto, Politecnico di Torino, Italy

Security and Privacy Protection in Information Processing Systems

Kai Rannenberg, Goethe University Frankfurt, Germany

Artificial Intelligence

Tharam Dillon, Curtin University, Bentley, Australia

Human-Computer Interaction

Annelise Mark Pejtersen, Center of Cognitive Systems Engineering, Denmark

Entertainment Computing

Ryohei Nakatsu, National University of Singapore 


\section{IFIP - The International Federation for Information Processing}

IFIP was founded in 1960 under the auspices of UNESCO, following the First World Computer Congress held in Paris the previous year. An umbrella organization for societies working in information processing, IFIP's aim is two-fold: to support information processing within its member countries and to encourage technology transfer to developing nations. As its mission statement clearly states,

IFIP's mission is to be the leading, truly international, apolitical organization which encourages and assists in the development, exploitation and application of information technology for the benefit of all people.

IFIP is a non-profitmaking organization, run almost solely by 2500 volunteers. It operates through a number of technical committees, which organize events and publications. IFIP's events range from an international congress to local seminars, but the most important are:

- The IFIP World Computer Congress, held every second year;

- Open conferences;

- Working conferences.

The flagship event is the IFIP World Computer Congress, at which both invited and contributed papers are presented. Contributed papers are rigorously refereed and the rejection rate is high.

As with the Congress, participation in the open conferences is open to all and papers may be invited or submitted. Again, submitted papers are stringently refereed.

The working conferences are structured differently. They are usually run by a working group and attendance is small and by invitation only. Their purpose is to create an atmosphere conducive to innovation and development. Refereeing is also rigorous and papers are subjected to extensive group discussion.

Publications arising from IFIP events vary. The papers presented at the IFIP World Computer Congress and at open conferences are published as conference proceedings, while the results of the working conferences are often published as collections of selected and edited papers.

Any national society whose primary activity is about information processing may apply to become a full member of IFIP, although full membership is restricted to one society per country. Full members are entitled to vote at the annual General Assembly, National societies preferring a less committed involvement may apply for associate or corresponding membership. Associate members enjoy the same benefits as full members, but without voting rights. Corresponding members are not represented in IFIP bodies. Affiliated membership is open to non-national societies, and individual and honorary membership schemes are also offered. 
Christos Emmanouilidis Marco Taisch

Dimitris Kiritsis (Eds.)

Advances in Production Management Systems

Competitive Manufacturing for Innovative Products and Services

IFIP WG 5.7 International Conference, APMS 2012 Rhodes, Greece, September 24-26, 2012

Revised Selected Papers, Part I

照 Springer 


\section{Volume Editors}

\section{Christos Emmanouilidis}

ATHENA Research and Innovation Centre

in Information Communication and Knowledge Technologies

ATHENA RIC Building, University Campus, Kimeria, 67100 Xanthi, Greece

E-mail: chrisem@ceti.athena-innovation.gr

Marco Taisch

Politecnico di Milano

Department of Management, Economics, and Industrial Engineering

Piazza Leonardo da Vinci, 32, 20133 Milano, Italy

E-mail: marco.taisch@polimi.it

Dimitris Kiritsis

École Polytechnique Fédérale de Lausanne (EPFL)

STI-IGM-LICP, ME A1 396, Station 9, 1015 Lausanne, Switzerland

E-mail: dimitris.kiritsis@epfl.ch

ISSN $1868-4238$

ISBN 978-3-642-40351-4

DOI 10.1007/978-3-642-40352-1

Springer Heidelberg Dordrecht London New York

Library of Congress Control Number: 2013944965
e-ISSN 1868-422X

e-ISBN 978-3-642-40352-1

\section{CR Subject Classification (1998): J.1, J.7, I.2, H.1, H.4, C.2, K.4.3}

(c) IFIP International Federation for Information Processing 2013

This work is subject to copyright. All rights are reserved by the Publisher, whether the whole or part of the material is concerned, specifically the rights of translation, reprinting, reuse of illustrations, recitation, broadcasting, reproduction on microfilms or in any other physical way, and transmission or information storage and retrieval, electronic adaptation, computer software, or by similar or dissimilar methodology now known or hereafter developed. Exempted from this legal reservation are brief excerpts in connection with reviews or scholarly analysis or material supplied specifically for the purpose of being entered and executed on a computer system, for exclusive use by the purchaser of the work. Duplication of this publication or parts thereof is permitted only under the provisions of the Copyright Law of the Publisher's location, in ist current version, and permission for use must always be obtained from Springer. Permissions for use may be obtained through RightsLink at the Copyright Clearance Center. Violations are liable to prosecution under the respective Copyright Law.

The use of general descriptive names, registered names, trademarks, service marks, etc. in this publication does not imply, even in the absence of a specific statement, that such names are exempt from the relevant protective laws and regulations and therefore free for general use.

While the advice and information in this book are believed to be true and accurate at the date of publication, neither the authors nor the editors nor the publisher can accept any legal responsibility for any errors or omissions that may be made. The publisher makes no warranty, express or implied, with respect to the material contained herein.

Typesetting: Camera-ready by author, data conversion by Scientific Publishing Services, Chennai, India

Printed on acid-free paper

Springer is part of Springer Science+Business Media (www.springer.com) 


\section{Preface}

Since the first conference that took place in Helsinki back in 1990, APMS is one of the major events and the official conference of the IFIP Working Group 5.7 on Advances in Production Management Systems. Recently, APMS successfully took place in Washington (USA, 2005), Wroclaw (Poland, 2006), Linköping (Sweden, 2007), Espoo (Finland, 2008), Bordeaux (France, 2009), Cernobbio (Italy, 2010), and Stavanger (Norway 2011).

APMS 2012 was sponsored by the IFIP WG 5.7 and co-sponsored by the ATHENA Research \& Innovation Centre and the Hellenic Maintenance Society in Greece. In an era of increased globalization and ever-pressing needs for improved efficiency, the APMS 2012 theme was "Competitive Manufacturing for Innovative Products and Services." In this setting, among the key elements of success in modern manufacturing and production management are:

- Resource Efficiency: the ability to perform in a resource-efficient manner throughout the lifecycle of a production process, product use or offered services.

- Key Enabling Technologies: the exploitation of the latest materials, manufacturing and production control technologies to support competitive and sustainable production.

- Networked Enterprise and Global Manufacturing and Supply Chains: the ability to operate as a globally interconnected organization and perform at a global scale, both at an intra- and inter-organizational scale.

- Knowledge Intensity and Exploitation: the efficient use of enterprise and human resources tangible and intangible knowledge, including efficient knowledge lifecycle management.

- Innovation: the ability to efficiently port $R \& D$ results into competitive new forms of production, products or services.

The APMS 2012 conference brought together leading experts from industry, academia and governmental organizations. They presented the latest developments in production management systems and debated how to shape up the future of competitive manufacturing. It comprised seven keynote talks and 36 sessions, including a dedicated Industry Panel Session, to offer the practitioners' view on linking research to industry, thus efficiently supporting the innovation process. The keynotes offered insight into cutting-edge issues of production management and its future, comprising the following talks:

- "A Business Perspective for Manufacturing Research," Jochen Rode, SAP

- "ICT-Driven Innovation in the Factories of the Future," Rolf Riemenschneider, European Commission

- "Sustainable Manufacturing: Towards a Competitive Industrial Base in Europe," Filip Geerts, CECIMO 
- "ICT Integration Challenges in Manufacturing: From the Device to the Enterprise Level," Thilo Sauter, Austrian Academy of Sciences

- "The IMS Global Platform Services for Manufacturing Research and Innovation," Dan Nagy, IMS

- "Energy Management Operations in Shipping Industry," Takis Varelas, DANAOS

- "The FoF PPP Call in WP2013 and Future Opportunities for Manufacturing R\&I in Horizon2020," Andrea Gentili, European Commission

Industry and academia converged in a stimulating Industry Panel Session, organized by Prof. Hermann Loedding and Dr. Gregor Alexander von Cieminski. The session theme was "Linking Research to Industry: The Practitioner's view on Competitive Manufacturing for Innovative Products and Services." The following panellist talks introduced the session discussion:

- "Leadership in Electronics Operations @Continental," Wolfgang Menzel, Continental

- "Integrating Industrial Needs with Academic Perspectives - Concept and Realization of the RWTH Aachen High Tech Campus," Volker Stich, RWTH Aachen

Wolfgang Menzel and Volker Stich were joined in the panel by Paul Schönsleben (ETH), Dan Nagy, IMS and Filip Geerts, CECIMO and debated about the crucial linkage between research and industry in order to shed light on what constitutes successful practices in bringing forward R\&D from the lab to industry-relevant innovation. The panel argued that higher education institutions should offer opportunities to students to undertake part of their studies in industry, with this being acknowledged and recognized as a formal part of education. Furthermore, industry could have more active presence within public research and educational campuses and FIR-RWTH Aachen was presented as an example of such an endeavor. Emphasis was placed on the industrial relevance of research, which would depart from theoretical solutions for "non-relevant" problems to conducting "relevant" research offering pragmatic and innovative solutions to industry.

Several special sessions were organized and ongoing research initiatives and projects presented their progress and results. A PhD Workshop was held prior to the conference, chaired by Sergio Cavalieri (University of Bergamo) and offered the opportunity to $\mathrm{PhD}$ researchers to present their research plans, objectives, and results to scientific discussants and gain valuable feedback to strengthen their research plan and activities.

At the conclusion of the conference, following the APMS tradition, the conference offered the following awards:

- Burbidge award for best paper to Dimitris Mourtzis (University of Patras)

- Burbidge award for best presentation to Morten Lund (University of Aalborg) 
- Best PhD workshop paper award to Elzbieta Pawlik (University of Strathclyde)

Approximately 240 academics, researchers, practitioners and scientists from 31 countries joined the APMS 2012 conference, sharing their expertise and providing insight into what constitutes the currently best practice in manufacturing and production management, while also projecting into the future of competitive manufacturing for innovative products and services. The conference involved a high-quality International Steering and a Scientific Committee of acknowledged excellence, while the review process involved 73 experts, all making key contributions to the conference success. The conference program included 196 regular presentations and $11 \mathrm{PhD}$ workshop presentations. The review process involved pre-conference extended abstracts reviews and a post-conference full paper review process, followed by a final paper submission by the authors, addressing the review comments. The result of this process is the present two-volume edited proceedings, comprising 182 full papers, organized under the following sections:

- Part I, Sustainability, including Energy Efficient Manufacturing, Sustainable Value Creation, Business Models and Strategies

- Part II, Design, Manufacturing and Production Management, including Mass Customization, Products of the Future and Manufacturing Systems Design, Advanced Design, Manufacturing and Production Management, as well as Robotics in Manufacturing

- Part III, Human Factors, Learning and Innovation, including Modern Learning in Manufacturing and Production Systems, Human Factors, Quality and Knowledge Management, as well as Innovation in Products and Services in Developing Countries

- Part IV, ICT and Emerging Technologies in Production Management, including Emerging Technologies in Production and the Lifecycle Management of Products and Assets, Enterprise Integration and Interoperability, as well as ICT for Manufacturing, Services and Production Management

- Part V, Product and Asset Lifecycle Management, including Product Lifecycle Management, Asset Lifecycle Management, as well as Performance and Risk Management

- Part VI, Services, Supply Chains and Operations, including Services, Managing International Operations, Supply Networks and Supply Chain Management, as well as Production Management, Operations and Logistics

We wish to acknowledge the support of Intelligent Manufacturing Systems (IMS) for the USB sticks and Lanyards for badges, as well as Prisma Electronics SA for sponsoring the APMS 2012 Welcome Reception.

We wish to thank the active members of the IFIP WG 5.7 community for their contribution and support of the conference, their support in the papers review process and the promotion of APMS 2012 through their networks and collaborating partners. Particular thanks are due to the ATHENA Research and Innovation Centre and the Hellenic Maintenance Society in Greece 
for co-sponsoring and supporting the conference and Zita Congress SA for their professional conference management services.

The conference was hosted on the island of Rhodes, Greece, a world-class destination, boasting a unique mixture of ancient and modern with holiday attractions and a continuing history of well over three millennia. According to mythology, Rhodes was created by the union of Helios, the Titan personalizing the sun, and the nymph Rhode. The ancient city of Rhodes hosted one of the ancient wonders of the world, the Colossus of Rhodes, a giant statute of Helios. Manufacturing and production management have made giant strides and continue to contribute toward a world of smart, sustainable and inclusive growth, but much more needs to be done and a global effort is needed to continue pushing toward such ends. The APMS 2012 conference constituted a focused effort and contribution in supporting such aims. We hope that the present two-volume set will be of interest to the industrial and academic communities working in the area of manufacturing and production management and the associated enabling technologies.

February 2013

Christos Emmanouilidis Marco Taisch Dimitris Kiritsis 


\section{Organization}

The APMS 2012 conference was sponsored by the IFIP WG 5.7 Advances in Production Management Systems, co-sponsored by the ATHENA Research \& Innovation Centre, in Information, Communication and Knowledge Technologies, Greece, and co-sponsored by the Hellenic Maintenance Society (HMS), Greece.

\section{Conference Chair}

Christos Emmanouilidis

ATHENA Research \& Innovation Centre, Greece

\section{Conference Co-chairs}

Marco Taisch

Dimitris Kiritsis
Politecnico di Milano, Italy

Ecole Polytechnique Fédérale de Lausanne, Switzerland

\section{APMS 2012 International Advisory Board}

Christos Emmanouilidis

Jan Frick

Dimitris Kiritsis

Vidosav Majstorovich

Riitta Smeds

Volker Stich

Marco Taisch

Bruno Vallespir
ATHENA R.I.C., Greece
University of Stavanger, Norway
EPFL, Switzerland
University of Belgrade, Serbia
Aalto University, Finland
FIR - RWTH Aachen, Germany
Politecnico di Milano, Italy
University of Bordeaux, France

\section{APMS 2012 Doctoral Workshop Chair}

Sergio Cavalieri

University of Bergamo, Italy

\section{APMS 2012 Local Organizing Committee}

Christos Emmanouilidis

Athanassios Kalogeras

Zacharias Kaplanidis

Irini Katti

Christos Koulamas

Dimitris Karampatzakis

Nikos Papathanasiou

Petros Pistofidis
ATHENA R.I.C, Greece

ATHENA R.I.C, Greece

Zita Congress, Greece

Zita Congress, Greece

ATHENA R.I.C, Greece

ATHENA R.I.C, Greece

ATHENA R.I.C, Greece

ATHENA R.I.C, Greece 


\section{APMS 2012 Conference Secretariat}

Zita Congress SA

Attica, Greece

\section{International Scientific Committee}

Bjørn Andersen

Abdelaziz Bouras

Luis M. Camarinha-Matos

Sergio Cavalieri

Stephen Childe

Alexandre Dolgui

Guy Doumeingts

Heidi C. Dreyer

Christos Emmanouilidis

Peter Falster

Rosanna Fornasiero

Jan Frick

Susumu Fujii

Marco Garetti

Antonios Gasteratos

Bernard Grabot

Robert W. Grubbström

Thomas Gulledge

Hans-Henrik Hvolby

Harinder Jagdev

Athanassios Kalogeras

Dimitris Kiritsis

Christos Koulamas

Andrew Kusiak

Lenka Landryova

Ming Lim

Hermann Lödding

Vidoslav D. Majstorovic

Kepa Mendibil

Kai Mertins

Hajime Mizuyama

Irenilza Nääs

Gilles Neubert
Norwegian University of Science and

Technology, Norway

University of Lyon, France

New University of Lisbon, Portugal

University of Bergamo, Italy

University of Exeter, UK

Ecole des Mines de Saint-Etienne, France

University Bordeaux, France

Norwegian University of Technology and Science, Norway

ATHENA Research \& Innovation Centre, Greece

Technical University of Denmark, Denmark ITIA-CNR, Italy

University of Stavanger, Norway

Sophia University, Japan

Politecnico di Milano, Italy

Democritus University of Thrace, Greece

Ecole Nationale d'Ingénieurs de TARBES, France

Linköping Institute of Technology, Sweden George Mason University, USA

University of Aalborg, Denmark

National University of Ireland, Ireland

ATHENA Research \& Innovation Centre,

Greece

EPFL, Switzerland

ATHENA Research \& Innovation Centre,

Greece

University of Iowa, USA

VSB Technical University Ostrava, Czech

Republic

Aston University, UK

Technical University of Hamburg, Germany

University of Belgrade, Serbia

University of Stratchclyde, UK

Fraunhofer IPK, Germany

Kyoto University, Japan

Universidade Paulista, Brazil

ESC Saint-Etienne, France 
Jan Olhager

Jens Ove Riis

Henk Jan Pels

Selwyn Piramuthu

Alberto Portioli

Asbjorn Rolstadas

Paul Schoensleben

Dan L. Shunk

Riitta Smeds

Vijay Srinivasan

Kenn Steger-Jensen

Kathryn E. Stecke

Volker Stich

Richard Lee Storch

Jan Ola Strandhagen

Stanisław Strzelczak

Marco Taisch

Ilias Tatsiopoulos

Sergio Terzi

Klaus-Dieter Thoben

Mario Tucci

Bruno Vallespir

Agostino Villa

Gregor Alexander von

Cieminski

Dan Wang

J.C. Wortmann

Iveta Zolotová

\section{External Reviewers}

Alexander von Cieminski, Gregor

Andersen Bjorn

Battaïa Olga

Bouras Abdelaziz

Camarinha-Matos Luis M.

Cavalieri Sergio

Childe Stephen

Corti Donatella

Dolgui Alexandre
Linköping University, Sweden

University of Alborg, Denmark

Eindhoven University of Technology,

Netherlands

University of Florida, USA

Politecnico di Milano, Italy

Norwegian University of Science and

Technology, Norway

ETH Zurich, Switzerland

Arizona State University, USA

Aalto University, Finland

National Institute of Standards and

Technology, USA

Aalborg University, Denmark

University of Texas, USA

FIR RWTH Aachen, Germany

University of Washington, USA

SINTEF, Norway

Warsaw University of Technology, Poland

Politecnico di Milano, Italy

National Technical University of Athens, Greece

University of Bergamo, Italy

University of Bremen/BIBA, Germany

University of Florence, Italy

University of Bordeaux, France

Politecnico di Torino, Italy

ZF Friedrichshafen AG, Germany

Harbin Institute of Technology, China

University of Groningen, The Netherlands

Technical University of Košice, Slovakia

ZF Friedrichshafen AG, Germany

Norwegian University of Science and

Technology, Norway

EMSE, France

Lumière University Lyon 2, France

New University of Lisbon, Portugal

University of Bergamo, Italy

University of Exeter, UK

Politecnico di Milano, Italy

Ecole des Mines de Saint-Etienne, France 
Dreyer Heidi C.

Emmanouilidis Christos

Errasti Ander

Evans Steve

Eynard Benoit

Falster Peter

Fornasiero Rosanna

Frick Jan

Garetti Marco

Gasteratos Antonios

Grabot Bernard

Grubbstrom Robert W.

Hvolby Hans-Henrik

Jagdev Harinder

Kaihara Toshiya

Kalogeras Athanasios

Karampatzakis Dimitris

Kiritsis Dimitris

Koulamas Christos

Krüger Volker

Landryova Lenka

Lim Ming

Loedding Hermann

Macchi Marco

Majstorovic Vidosav D.

Mandic Vesna

May Gökan

Mendibil Kepa

Mertins Kai

Mizuyama Hajime

Nääs Irenilza

Netland Torbjoern H.

Neubert Gilles

Olhager Jan

Oliveira Manuel F.
Norwegian University of Technology and Science (NTNU), Norway

ATHENA Research \& Innovation Centre, Greece

TECNUN University of Navarra, Spain

University of Cambridge, UK

Université de Technologie de Compiègne, France

Technical University of Denmark, Denmark

ITIA-cnr, Italy

University of Stavanger, Norway

Politecnico di Milano, Italy

Democritus University of Thrace, Greece

Ecole Nationale d'Ingenieurs de TARBES, France

Linkoping Institute of Technology, Sweden Aalborg University, Denmark

National University of Ireland, Galway, Ireland Kobe University, Japan

ATHENA Research \& Innovation Centre, Greece

ATHENA Research \& Innovation Centre, Greece

EPFL, Switzerland

ATHENA Research \& Innovation Centre, Greece

Aalborg University, Denmark

VSB - Technical University of Ostrava, Czech Republic

University of Derby, UK

Technical University of Hamburg, Germany

Politecnico di Milano, Italy

University of Belgrade, MEF, Serbia

University of Kragujevac, Serbia

Politecnico di Milano, Italy

University of Strathclyde, UK

Fraunhofer IPK/TU Berlin, Germany

Aoyama Gakuin University, Japan

Paulista University-UNIP, Brazil

Norwegian University of Science and

Technology, Norway

Ecole Supérieure de Commerce, France

Lund University, Sweden

SINTEF, Norway 
Pels Henk Jan

Piramuthu Selwyn

Pistofidis Petros

Portioli Alberto

Pourabdollahian Borzoo

Pourabdollahian Golboo

Riis Jens Ove

Sauter Thilo

Schoensleben Paul

Shunk Dan L.

Smeds Riitta

Srinivasan Vijay

Stahl Bojan

Stecke Kathryn E.

Steger-Jensen Kenn

Stich Volker

Storch Richard Lee

Strzelczak Stanislaw

Taisch Marco

Tatsiopoulos Ilias

Terzi Sergio

Thoben Klaus-Dieter

Tucci Mario

Uusitalo Teuvo

Vallespir Bruno

Vasyutynskyy Volodymyr

Villa Agostino

Wortmann J.C.

Zolotova Iveta
Eindhoven University of Technology,

The Netherlands

University of Florida, USA

ATHENA Research \& Innovation Centre,

Greece

Politecnico di Milano, Italy

Politecnico di Milano, Italy

Politecnico di Milano, Italy

Aalborg University, Denmark

Austrian Academy of Sciences, Austria

ETH Zurich, Switzerland

Arizona State University, USA

Aalto University, Finland

National Institute of Standards and

Technology, USA

Politecnico di Milano, Italy

University of Texas at Dallas, USA

Aalborg University, Denmark

FIR RWTH Aachen, Germany

University of Washington, USA

Warsaw University of Technology, Poland

Politecnico di Milano, Italy

National Technical University of Athens, Greece

University of Bergamo, Italy

BIBA - Bremer Institut für Produktion und

Logistik, Germany

Università di Firenze, Italy

VTT Technical Research Centre of Finland, Finland

Bordeaux University, France

SAP Research Dresden, Germany

Politecnico di Torino, Italy

University of Groningen, The Netherlands

Technical University of Kosice, Slovakia 


\section{Table of Contents - Part I}

\section{Part I: Sustainability}

\section{Energy Efficient Manufacturing}

Toward Energy Efficient Manufacturing: A Study on Practices and

Viewpoint of the Industry . . . . . . . . . . . . . . . . . 1

Gökan May, Marco Taisch, Bojan Stahl, and Vahid Sadr

Energy Efficient Production through a Modified -Green-PPC and a Communication Framework for the Energy Supply Chain to Manage

Energy Consumption and Information .................. 9

Ulrich Brandenburg, Sebastian Kropp, Jorge Sunyer, and

Daniel Batalla-Navarro

Energy-Efficient Machining via Energy Data Integration . . . . . . . . . .

Tao Peng, Xun Xu, and Juhani Heilala

An ICT Supported Holistic Approach for Qualitative and Quantitative

Energy Efficiency Evaluation in Manufacturing Company ...........

Hendro Wicaksono, Kiril Aleksandrov, Sven Rogalski, and

Jivka Ovtcharova

How Energy Recovery Can Reshape Storage Assignment in Automated

Warehouses .....................................

Antonella Meneghetti and Luca Monti

Modeling Green Fabs - A Queuing Theory Approach for Evaluating

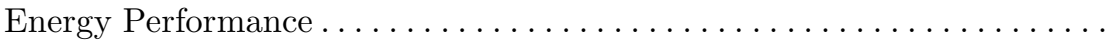

Hyun Woo Jeon and Vittaldas V. Prabhu

Analyzing Energy Consumption for Factory and Logistics Planning

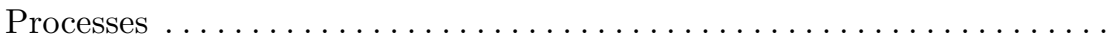

Egon Müller, Hendrik Hopf, and Manuela Krones

Energy Implications in the Single-Vendor Single-Buyer Integrated

Production Inventory Model . . . . . . . . . . . . . . . . . .

Simone Zanoni, Laura Bettoni, and Christoph H. Glock

An Extended Energy Value Stream Approach Applied on the

Electronics Industry . . . . . . . . . . . . . . . . . . .

Gerrit Bogdanski, Malte Schönemann, Sebastian Thiede,

Stefan Andrew, and Christoph Herrmann 
An Approach for Energy Saving in the Compound Feed Production .... .

Marc Allan Redecker and Klaus-Dieter Thoben

Bridging the Gap between Energy Management Systems and Machine Tools - Embedded Energy Efficiency in Production Planning and Control ................................

Manuel Rippel, Olga Willner, Johannes Plehn, and Paul Schönsleben

Energy Efficient Production Planning: A Joint Cognitive Systems Approach . . . ............................

Connor Upton, Fergus Quilligan, Carlos García-Santiago, and Asier González-González

Using Internet of Things to Improve Eco-efficiency in Manufacturing:

A Review on Available Knowledge and a Framework for IoT

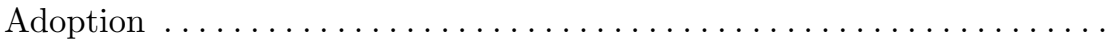

Giovanni Miragliotta and Fadi Shrouf

An Investigation into Minimising Total Energy Consumption, Total Energy Cost and Total Tardiness Based on a Rolling Blackout Policy in a Job Shop . . . . . . . . . . . . . . . . . . . . . . . . . .

Ying Liu, Niels Lohse, Sanja Petrovic, and Nabil Gindy

Requirements Analysis and Definition for Eco-factories: The Case of

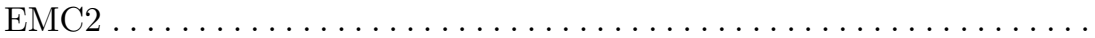

Marco Taisch and Bojan Stahl

Energy Efficient Process Planning System - The ENEPLAN Project ...

Paolo Calefati, John Pandremenos, Apostolos Fysikopoulos, and George Chryssolouris

Energy Efficiency Optimisation in Heat Treatment Process Design . . . . .

Iñigo Mendikoa, Mikel Sorli, Alberto Armijo, Laura Garcia,

Luis Erausquin, Mario Insunza, Jon Bilbao, Hakan Friden, Anders Björk, Linus Bergfors, Romualdas Skema, Robertas Alzbutas, and Tomas Iesmantas

Evaluation and Calculation of Dynamics in Environmental Impact Assessment.............................

Björn Johansson, Jon Andersson, Erik Lindskog, Jonatan Berglund, and Anders Skoogh

Discrete Part Manufacturing Energy Efficiency Improvements with

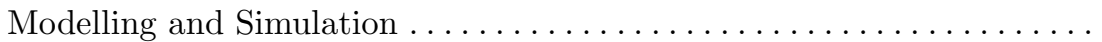

Juhani Heilala, Marja Paju, Jari Montonen, Reino Ruusu, Mikel Sorli, Alberto Armijo, Pablo Bermell-Garcia, Simon Astwood, and Santiago Quintana 
A Parallelizable Heuristic for Solving the Generic Materials and Operations Planning in a Supply Chain Network: A Case Study from the Automotive Industry . . . . . . . . . . . . . . . . . . .

Julien Maheut and Jose Pedro Garcia-Sabater

Factory Modelling: Combining Energy Modelling for Buildings and

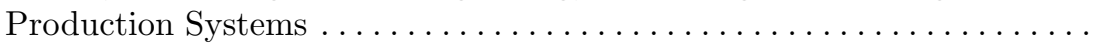

Peter D. Ball, Melanie Despeisse, Steve Evans, Rick M. Greenough,

Steve B. Hope, Ruth Kerrigan, Andrew Levers, Peter Lunt,

Vincent Murray, Mike R. Oates, Richard Quincey, Li Shao,

Timothy Waltniel, and Andrew J. Wright

\section{Sustainable Value Creation, Business Models and Strategies}

Business Modelling for Sustainable Manufacturing . . . . . . . . . . . . 166 Maria Holgado, Donatella Corti, Marco Macchi, Padmakshi Rana, Samuel W. Short, and Steve Evans

Embedding Sustainability in Business Modelling through Multi-

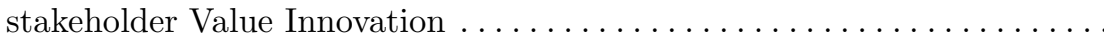

Samuel W. Short, Padmakshi Rana, Nancy M.P. Bocken, and Steve Evans

Toward Sustainability Governance in Manufacturing Networks

Teuvo Uusitalo, Markku Reunanen, Katri Valkokari,

Pasi Valkokari, and Katariina Palomäki

Implementation of Sustainability in Ongoing Supply Chain

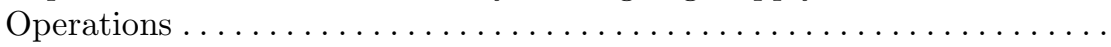

Liliyana Makarova Jørsfeldt, Peter Meulengracht Jensen, and Brian Vejrum Waehrens

Modular Framework for Reliable LCA-Based Indicators Supporting Supplier Selection within Complex Supply Chains ..............

Carlo Brondi, Rosanna Fornasiero, Manfredi Vale,

Ludovico Vidali, and Federico Brugnoli

Sustainable Food Supply Chains: Towards a Framework for Waste

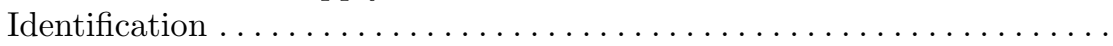

Lukas Chabada, Heidi Carin Dreyer, Anita Romsdal, and Daryl John Powell

A Classification of Industrial Symbiosis Networks: A Focus on Materials and Energy Recovery ........................

Vito Albino, Achille Claudio Garavelli, and

Vincenzo Alessio Romano 
Performance Evaluation in Sustainability Conscious Manufacturing

Companies by Using TOPSIS Method ................ Merve Kılıç and Seren Özmehmet Taşan

A Decision-Aiding Approach for Residential PhotoVoltaic System Choice: An Application to the French Context . . . . . . . . . . . . . Fredy Huaylla, Lamia Berrah, and Vincent Cliville

Design of Controlling Supported Sustainability of Manufacturing Enterprises ... Eryk Gtodziński

\section{Part II: Design, Manufacturing and Production Management}

\section{Mass Customization}

Modularization - Enabler for Shop Floor Involvement in Improvement

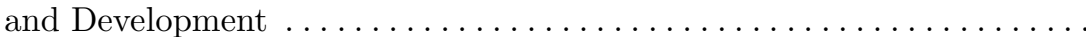

Bjørnar Henriksen, Lars Skjelstad, Eva Amdahl Seim, and

Carl Christian Røstad

Comparison of Criticality of Configuration Choices for Market Price

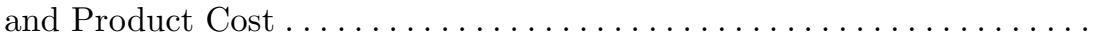

Peter Nielsen and Thomas Ditlev Brunoe

The Multiple Faces of Mass Customization: Product Design, Process Design and Supply Chain Design .....................

Nico J. Vandaele and Catherine J. Decouttere

Development of a Business Process Matrix for Structuring the Implications of Using Configurators in an Engineer-To-Order

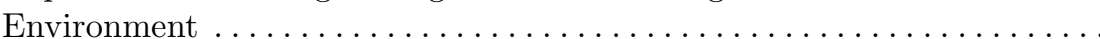

Olga Willner, Manuel Rippel, Matthias Wandfluh, and Paul Schönsleben

Designing Rotationally Symmetric Products for Multi-variant Mass Production by Using Production-Technical Solution Space. . . . . . . . . . .

Günther Schuh, Till Potente, Christina Thomas, and Stephan Schmitz

Robotics in the Construction Industry: Mass Customization or Digital

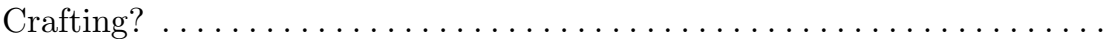


Simulation-Based Design of Production Networks for Manufacturing of Personalised Products ..........................

Dimitris Mourtzis, Michalis Doukas, and Foivos Psarommatis

An Empirical Based Proposal for Mass Customization Business Model

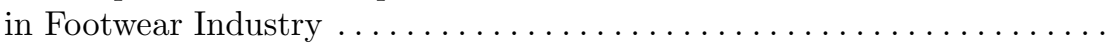
Golboo Pourabdollahian, Donatella Corti, Chiara Galbusera, and Julio Cesar Kostycz Silva

Mass Customized Large Scale Production System with Learning Curve Consideration . . . . . . . . . . . . . . . . . . . . . . . . . . .

KuoWei Chen and Richard Lee Storch

Event-Driven Order Rescheduling Model for Just-In-Sequence Deliveries to a Mixed-Model Assembly Line . . . . . . . . . . . . . . . . . . . . . . . . . .

Georg Heinecke, Jonathan Köber, Raffaello Lepratti, Steffen Lamparter, and Andreas Kunz

Support to Order Management and Collaborative Production of Customised Garments for Specific Target Groups . . . . . . . . . . . . .

Eva Coscia, Michele Sesana, and Rosanna Fornasiero

Modeling and Simulation Tool for Sustainable MC Supply Chain

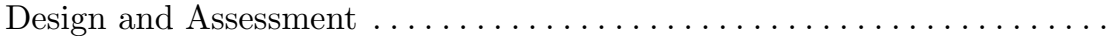

Paolo Pedrazzoli, Marino Alge, Andrea Bettoni, and Luca Canetta

Agent Based Resources Allocation in Job Shop with Re-entrant Features: A Benchmarking Analysis . . . . . . . . . . . . . . Matteo Mario Savino and Antonio Mazza

\section{Products of the Future and Manufacturing Systems Design}

Design of a Taxation System to Promote Electric Vehicles

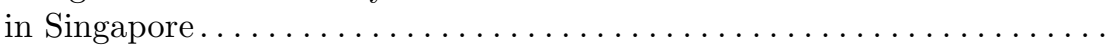

Seng Tat Chua and Masaru Nakano

Knowledge Management in Set Based Lean Product Development Process . . . . . . . . . . . . . . . . . . . . . . . . . . . . . . .

Robert Furian, Frank von Lacroix, Dragan Stokic,

Ana Correia, Cristina Grama, Stefan Faltus, Maksim Maksimovic, Karl-Heinrich Grote, and Christiane Beyer

Design of Fundamental Ontology for Manufacturing Product Lifecycle Applications..............................

Dimitris Kiritsis, Soumaya El Kadiri, Apostolos Perdikakis, Ana Milicic, Dimitris Alexandrou, and Kostas Pardalis 
Proposal of an Assessment Model for New Product Development . . . . . . . 383

Monica Rossi, Sergio Terzi, and Marco Garetti

Multi-objective Optimization of Product Life-Cycle Costs and Environmental Impacts . . . . . . . . . . . . . . . . . . .

Daniele Cerri, Marco Taisch, and Sergio Terzi

A Stochastic Formulation of the Disassembly Line Balancing Problem . . . . . . . . . . . . . . . . . . . . . . . . . . . . .

Mohand Lounes Bentaha, Olga Battaïa, and Alexandre Dolgui

Incorporating Regularity of Required Workload to the MMSP-W with Serial Workstations and Free Interruption of the Operations . . . . . . . . Joaquín Bautista, Rocío Alfaro, and Alberto Cano

Incorporating Ergonomics Factors into the TSALBP

Joaquín Bautista, Cristina Batalla, and Rocío Alfaro

Critical Factors for Successful User-Supplier Integration in the Production System Design Process .....................

Jessica Bruch and Monica Bellgran

\section{Advanced Design, Manufacturing and Production Management}

Current State and Future Perspective Research on Lean

Remanufacturing - Focusing on the Automotive Industry . . . . . . . . .

Elzbieta Pawlik, Winifred Ijomah, and Jonathan Corney

Understanding Product State Relations within Manufacturing

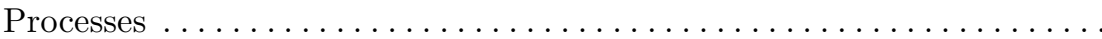

Benjamin Knoke, Thorsten Wuest, and Klaus-Dieter Thoben

Universal Simulation Model in Witness Software for Verification and Following Optimization of the Handling Equipment .............

Jiři Holik and Lenka Landryová

An Adaptive Kanban and Production Capacity Control Mechanism ....

Léo Le Pallec Marand, Yo Sakata, Daisuke Hirotani,

Katsumi Morikawa, and Katsuhiko Takahashi

Intelligent Manufacturing Systems: Controlling Elastic Springback in

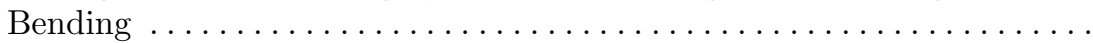

Torgeir Welo 
Splitting or Sharing Resources at the Process Level: An Automotive

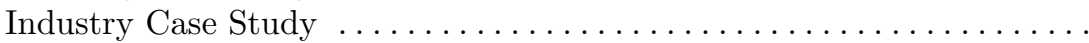

Dag E. Gotteberg Haartveit, Marco Semini, and Erlend Alfnes

Optimization of Flexible Assembly Systems for Electrical Motors....... . Mirlind Bruqi, Ramë Likaj, and Jorgaq Kaqani

Flexible and Reconfigurable Layouts in Complex Manufacturing

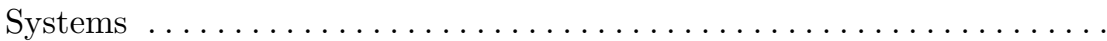

Maria Manuela Azevedo, José António Crispim, and Jorge Pinho de Sousa

Cost Management Practices in Collaborative Product Development

Processes ...................................

Carlos Barbosa, Paulo Afonso, and Manuel Nunes

The Multidisciplinary Virtual Product Development Integrates the Influence of Die Casting Defects in the Mechanical Response . . . . . . . . 502

Nicola Gramegna, Iñigo Loizaga, Susana Berrocal, Franco Bonollo,

Giulio Timelli, and Stefano Ferraro

Design and Simulation-Based Testing of a Prediction Market System

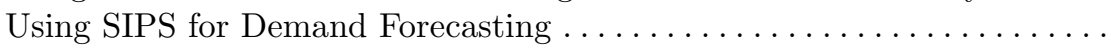

Hajime Mizuyama

\section{Robotics in Manufacturing}

Multi-objective Genetic Algorithm for Real-World Mobile Robot

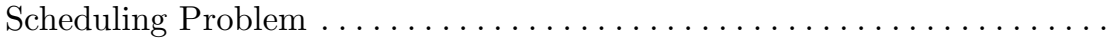

Quang-Vinh Dang, Izabela Nielsen, and Kenn Steger-Jensen

Multi-camera 3D Object Reconstruction for Industrial Automation . . . . .

Malamati Bitzidou, Dimitrios Chrysostomou, and

Antonios Gasteratos

Multimodal Processes Rescheduling

Grzegorz Bocewicz, Zbigniew A. Banaszak, Peter Nielsen, and Quang-Vinh Dang

Novel Automated Production System for the Footwear Industry........

Silvio Cocuzza, Rosanna Fornasiero, and Stefano Debei

Safety-Guided Design Concerning Standardization's Requirements of Mowing Robots . . . . . . . . . . . . . . . . . . . . . . . . . . . . . . . Spyridon G. Mouroutsos and Eleftheria Mitka 


\section{Part III: Human Factors, Learning and Innovation}

\section{Modern Learning in Manufacturing and Production Systems}

Applying Serious Games in Lean Manufacturing Training ............

Mourad Messaadia, Ahmed Bufardi, Julien Le Duigou,

Hadrien Szigeti, Benoit Eynard, and Dimitris Kiritsis

Flow and Physical Objects in Experiential Learning for Industrial Engineering Education............................... 566

David Jentsch, Ralph Riedel, and Egon Mueller

Context Aware E-Support in E-Maintenance ...................

Nikos Papathanassiou, Christos Emmanouilidis,

Petros Pistofidis, and Dimitris Karampatzakis

Using Behavioral Indicators to Assess Competences in a Sustainable Manufacturing Learning Scenario ..........................

Heiko Duin, Gregor Cerinsek, Manuel Oliveira, Michael Bedek, and Slavko Dolinsek

Lean Product Development: Serious Game and Evaluation of the

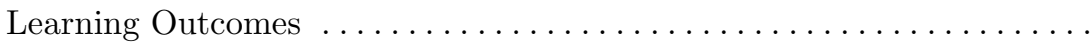

Endris Kerga, Armin Akaberi, Marco Taisch, Monica Rossi, and Sergio Terzi

Learning PLM System with a Serious Game 598

Philippe Pernelle, Stephane Talbot, Thibault Carron, and Jean-Charles Marty

Beware of the Robot: A Highly Interactive and Immersive Virtual Reality Training Application in Robotic Manufacturing Systems ....... 606 Elias Matsas, Dimitrios Batras, and George-Christopher Vosniakos

Educational Framework of Product Lifecycle Management Issues for

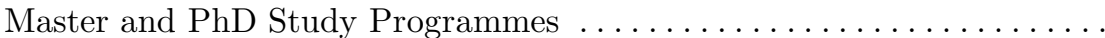
Milan Edl

The Use of Serious Games in the Education of Engineers............ Jannicke Madeleine Baalsrud Hauge, Borzoo Pourabdollahian, and Johann C.K.H. Riedel

Integrating Competence Management into a Coupled Project-System

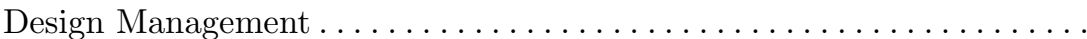
Arz Wehbe, Christophe Merlo, and Véronique Pilnière 
Model of Skills Development at the Operational Level Applied to the

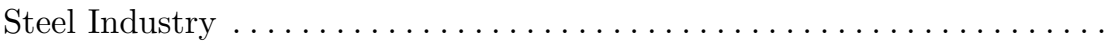
638

Ulysses Martins Moreira Filho and Pedro Luiz de Oliveira Costa Neto

\section{Human Factors, Quality and Knowledge Management}

Success Factors for PDCA as Continuous Improvement Method in Product Development ................................

Eirin Lodgaard, Inger Gamme, and Knut Einar Aasland

Supporting Production System Development through the Obeya Concept ......................................

Siavash Javadi, Sasha Shahbazi, and Mats Jackson

Measurement, Classification and Evaluation of the Innovation Process and the Identification of Indicators in Relation to the Performance Assessment of Company's Innovation Zones ...................

Peter Kubičko, Lenka Landryová, Roman Mihal', and Iveta Zolotová

The Internet of Experiences -Towards an Experience-Centred

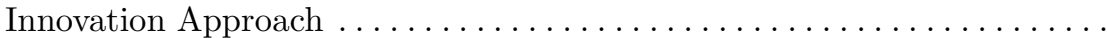

Stefan Wellsandt, Thorsten Wuest, Christopher Durugbo, and Klaus-Dieter Thoben

Innovating a Business Model for Services with Storytelling ........... 677 Morten Lund

Business Strategy and Innovativeness: Results from an Empirical

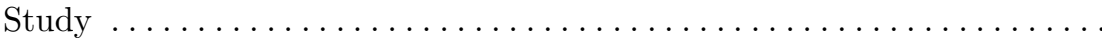

Gündüz Ulusoy, Gürhan Günday, Kemal Kılıç, and Lütfihak Alpkan

International R\&D and Manufacturing Networks: Dynamism, Structure

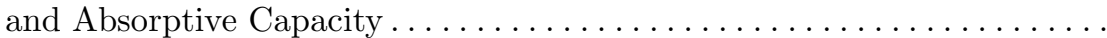

Patricia Deflorin, Maike Scherrer-Rathje, and Helmut Dietl

\section{Innovation in Products and Services in Developing Countries}

Building a Conceptual Model for Analyzing Sustainability Projects Aiming at Technology Transfer: A Terminological Approach .......... 701 Deise Rocha Martins dos Santos Oliveira, Irenilza de Alencar Nääs, Ivo Pierozzi Júnior, and Oduvaldo Vendrametto

Finding Optimal Resources for IT Services .................. 708 Sumit Raut and Muralidharan Somasundaram 
Development of Engineering Competencies in Brazil and Innovation

Policies, an Overview of the Automotive Sector .

Renato Perrotta and Oduvaldo Vendrametto

Holistic Vision of Sustainability in the Production Chain in Oil

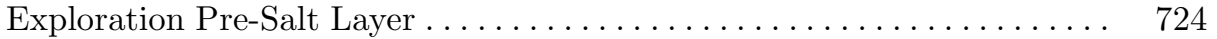

Alessandro Luiz da Silva, Mônica Franchi Carniello, and

José Luís Gomes da Silva

Applicability of Risk Process in Software Projects in Accordance with

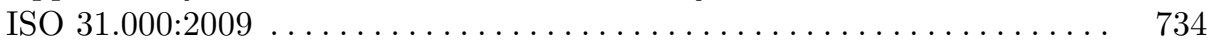

Marcelo Nogueira and Ricardo J. Machado

Author Index ............................. 743 


\section{Table of Contents - Part II}

\section{Part IV: ICT and Emerging Technologies in Production Management}

\section{Emerging Technologies in Production and the Lifecycle Management of Products and Assets}

Analysis of Manufacturing Process Sequences, Using Machine Learning on Intermediate Product States (as Process Proxy Data) . . . . . . . . .

Thorsten Wuest, Christopher Irgens, and Klaus-Dieter Thoben

Improving Tree-Based Classification Rules Using a Particle Swarm

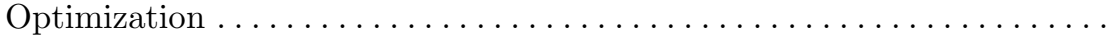

Chi-Hyuck Jun, Yun-Ju Cho, and Hyeseon Lee

Profiling Context Awareness in Mobile and Cloud Based Engineering

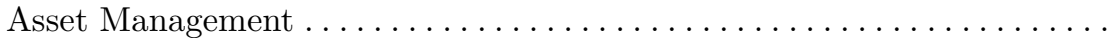

Petros Pistofidis and Christos Emmanouilidis

Seamless Access to Sensor Networks for Enhanced Manufacturing

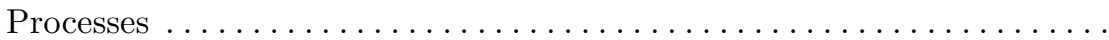

Kostas Kalaboukas, Borislav Jerabek, Rok Lah, and Freek van Polen

Wireless Sensor Network Technologies for Condition Monitoring of Industrial Assets. . . . . . . . . . . . . . . . . . . . .

Spilios Giannoulis, Christos Koulamas, Christos Emmanouilidis,

Petros Pistofidis, and Dimitris Karampatzakis

A Critical Evaluation of RFID in Manufacturing ...............

Wei Zhou and Selwyn Piramuthu

Semantic Data Model for Operation and Maintenance of the Engineering Asset ............................ Andreas Koukias, Dražen Nadoveza, and Dimitris Kiritsis

\section{Enterprise Integration and Interoperability}

Towards Changeable Production Systems - Integration of the Internal and External Flow of Information as an Enabler for Real-Time Production Planning and Controlling ................. 
Integrated Model-Based Manufacturing for Rapid Product and Process Development ...........................

Vesna Mandic, Radomir Radisa, Vladan Lukovic, and Milan Curcic

Real-Time Production Monitoring in Large Heterogeneous

Environments ...........................

Arne Schramm, Bernhard Wolf, Raik Hartung, and André Preußner

Ontology-Based Flexible Multi Agent Systems Design and Deployment

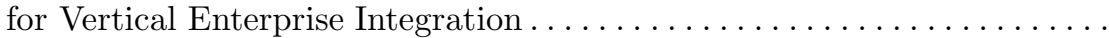

Christos Alexakos, Manos Georgoudakis,

Athanasios P. Kalogeras, and Spiridon L. Likothanassis

MANU Building - Bringing together Manufacturing Automation and

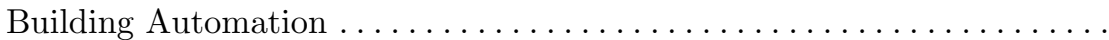

Aleksey Bratukhin, Albert Treytl, and Thilo Sauter

Formal Specification of Batch Scheduling Problems: A Step toward

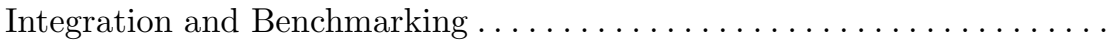

Gabriela Patricia Henning

\section{ICT for Manufacturing, Services and Production Management}

Introducing "2.0" Functionalities in an ERP . . . . . . . . . . .

Bernard Grabot, Raymond Houé, Fabien Lauroua, and Anne Mayère

Designing and Implementing a Web Platform to Support SMEs

in Collaborative Product Development ...................

Marco Formentini, Michela Lolli, and Alberto Felice De Toni

Exploring the Impact of ICT in CPFR: A Case Study of an APS

System in a Norwegian Pharmacy Supply Chain ...............

Maria Kollberg Thomassen, Heidi Dreyer, and Patrik Jonsson

MES Support for Lean Production

Daryl Powell, Andreas Binder, and Emrah Arica

Handling Unexpected Events in Production Activity Control Systems... 136

Emrah Arica, Jan Ola Strandhagen, and Hans-Henrik Hvolby

Analyzing IT Supported Production Control by Relating Petri

Nets and UML Static Structure Diagrams . . . . . . . . . . . . . . .

Henk Jan Pels 
Enabling Information Sharing in a Port . . . . . . . . . . . . . 152

Peter Bjerg Olesen, Hans-Henrik Hvolby, and

Iskra Dukovska-Popovska

Designing a Lifecycle Integrated Data Network for Remanufacturing

Using RFID Technology . . . . . . . . . . . . . . . . . . . . 160

Young-woo Kim and Jinwoo Park

\section{Part V: Product and Asset Lifecycle Management}

\section{Product Lifecycle Management}

Implementing Sustainable Supply Chain in PLM . . . . . . . . . . . . 168

Maria Bonvehi Rosich, Julien Le Duigou, and

Magali Bosch-Mauchand

Full Exploitation of Product Lifecycle Management by Integrating

Static and Dynamic Viewpoints . . . . . . . . . . . . . . . . . . 176

Dario Antonelli, Giulia Bruno, Antonia Schwichtenberg, and

Agostino Villa

Enterprise Information Systems' Interoperability: Focus on PLM

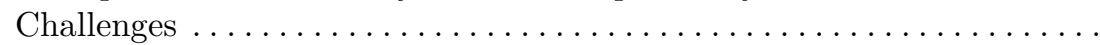

Dorsaf Elheni-Daldoul, Julien Le Duigou, Benoit Eynard, and

Sonia Hajri-Gabouj

Closed-Loop Life Cycle Management Concept for Lightweight

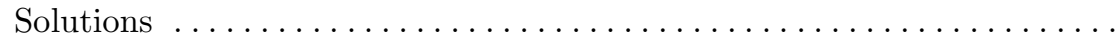

Fatih Karakoyun and Dimitris Kiritsis

Design Support Based onto Knowledge to Increase Product

Reliability and Allow Optimized Abacus Development ............. 200

Jérémy Boxberger, Daniel Schlegel, Nahdir Lebaal, and

Samuel Gomes

Towards an Harmonious and Integrated Management Approach

for Lifecycle Planning ... . . . . . . . . . . . . . . . . . . . . . 208

Frédéric Demoly, Samuel Deniaud, and Samuel Gomes

An MDA Approach for PLM System Design ..................

Onur Yildiz, Lilia Gzara, Philippe Pernelle, and Michel Tollenaere

\section{Asset Lifecycle Management}

Dynamic Alarm Management in Next Generation Process Control

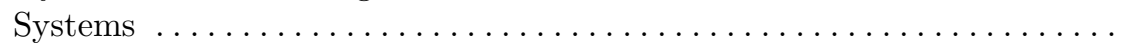

Eva Jerhotova, Marek Sikora, and Petr Stluka 
Sustainable Layout Planning Requirements by Integration of Discrete

Event Simulation Analysis (DES) with Life Cycle Assessment (LCA) ...

Victor Emmanuel de Oliveira Gomes, Durval Joao De Barba

Jr, Jefferson de Oliveira Gomes, Karl-Heinrich Grote, and

Christiane Beyer

Equipment's Prognostics Using Logical Analysis of Data . . . . . . . . . .

Alireza Ghasemi, Sasan Esmaeili, and Soumaya Yacout

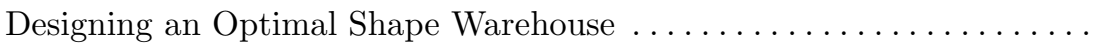

Lucio Compagno, Diego D'Urso, and Natalia Trapani

A Fourth Party Energy Provider for the Construction Value Chain:

Identifying Needs and Establishing Requirements .............

Sergio Cavalieri, Stefano Ierace, Nicola Pedrali, and Roberto Pinto

\section{Performance and Risk Management}

Performance Measurement Systems for Craft-Oriented Small

Enterprises . . . . . . . . . . . . . . . . . . . . . . . . . .

Inger Gamme, Eva Amdahl Seim, and Eirin Lodgaard

State-of-the-Art Review on Operational Resilience: Concept, Scope and

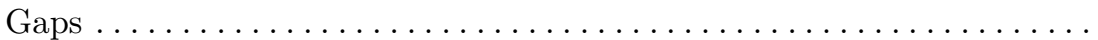

Seyoum Eshetu Birkie, Paolo Trucco, and Matti Kaulio

Modeling and Presentation of Interdependencies between Key

Performance Indicators for Visual Analysis Support . . . . . . . . . . .

Stefan Hesse, Volodymyr Vasyutynskyy, Martin Rosjat, and

Christian Hengstler

Reference Model Concept for Structuring and Representing Performance

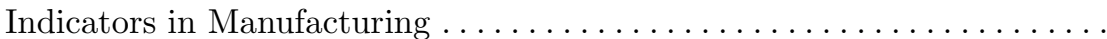

Stefan Hesse, Bernhard Wolf, Martin Rosjat, Dražen Nadoveza, and

George Pintzos

Productivity Measurement and Improvements: A Theoretical

Model and Applications from the Manufacturing Industry . . . . . . . . .

Peter Almström 


\section{Part VI: Services, Supply Chains and Operations}

\section{Services}

Manufacturing Service Ecosystems: Towards a New Model to Support Service Innovation Based on Extended Products . . . . . . . . . . . . . . 305

Stefan Wiesner, Ingo Westphal, Manuel Hirsch, and Klaus-Dieter Thoben

Multiagent System-Based Simulation Method of Service Diffusion in Consumer Networks - Application to Repeatedly Purchased Plural

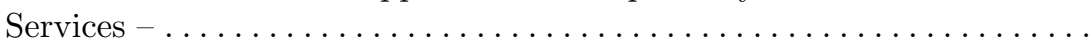

Nobutada Fujii, Toshiya Kaihara, and Tomoya Yoshikawa

Manufacturing Service Innovation Ecosystem . . . . . . . . . . . .

Marco Taisch, Mohammadreza Heydari Alamdari, and Christiano Zanetti

Improvement Method of Service Productivity for Taxi Company . . . . . . Takashi Tanizaki

The Servitization of Manufacturing: A Methodology for the Development of After-Sales Services . . . . . . . . . . . . . . . . . . .

Ottar Bakås, Daryl Powell, Barbara Resta, and Paolo Gaiardelli

Do Consumers Select Food Products Based on Carbon Dioxide

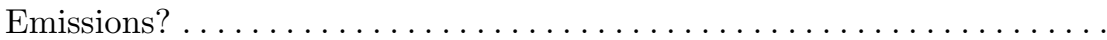

Keiko Aoki and Kenju Akai

A Choice Experiment for Air Travel Services Kenju Akai, Keiko Aoki, and Nariaki Nishino

Product-Service Systems Modelling and Simulation as a Strategic

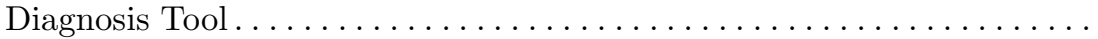

Thècle Alix and Gregory Zacharewicz

Contribution to the Development of a Conceptual Model of Service and

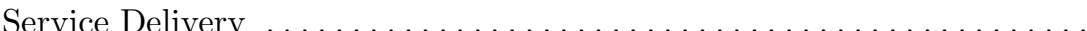

Wael Touzi, Thècle Alix, and Bruno Vallespir

PSS Production Systems: A Simulation Approach for Change

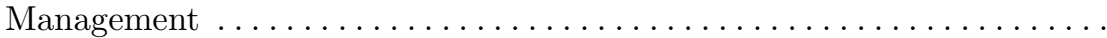

Guillaume Marquès, Malik Chalal, and Xavier Boucher

Improving Customer's Subjective Waiting Time Introducing Digital

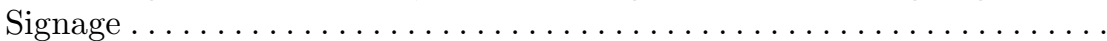

Takeshi Shimamura, Toshiya Kaihara, Nobutada Fujii, and Takeshi Takenaka 
Framework for Lean Management in Industrial Services .............

Günther Schuh and Philipp Stüer

The Role of IT for Extended Products' Evolution into Product Service

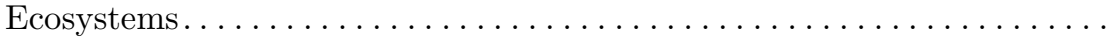

Klaus-Dieter Thoben and J.C. (Hans) Wortmann

Demand Control Loops for a Global Spare Parts Management . . . . . . . .

Uwe Dombrowski, Sebastian Weckenborg, and Michael Mederer

The Value and Management Practices of Installed Base Information in Product-Service Systems . . . . . . . . . . . . . . . . . . . . . . . .

Nicola Saccani, Andrea Alghisi, and Jukka Borgman

Reference Decision Models in the Medico-social Service Sector . . . . . . . .

Henri Kromm and Yves Ducq

Service Model for the Service Configuration .................

Jose Angel Lakunza, Juan Carlos Astiazaran, and Maria Elejoste

\section{Managing International Operations}

Benefits and Risks in Dynamic Manufacturing Networks . . . . . . . . .

Ourania Markaki, Panagiotis Kokkinakos, Dimitrios Panopoulos,

Sotirios Koussouris, and Dimitrios Askounis

Dynamic Manufacturing Networks Monitoring and Governance ........ 446

Panagiotis Kokkinakos, Ourania Markaki, Dimitrios Panopoulos,

Sotirios Koussouris, and Dimitrios Askounis

The Insignificant Role of National Culture in Global Lean

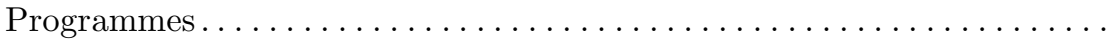

Torbjørn H. Netland, Miguel Mediavilla, and Ander Errasti

Methodology to Identify SMEs Needs of Internationalised and Collaborative Networks . . . . . . . . . . . . . . . . . . . . .

Beatriz Andrés and Raúl Poler

Framework for Improving the Design and Configuration Process

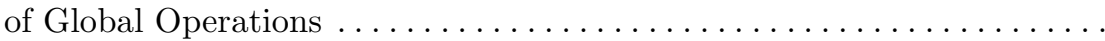

S. Martinez, A. Errasti, J. Santos, and M. Mediavilla

What to Offshore, What to Produce at Home? A Methodology . . . . . . .

Marco Semini, Børge Sjøbakk, and Erlend Alfnes

Idiosyncratic Behavior of Globally Distributed Manufacturing 487

Stanislaw Strzelczak 
Improving the Industrialization of a New Product in an International Production Network: A Case Study from the Machinery Industry ......

Donatella Corti and Saransh Choudhury

Optimize Resource Utilization at Multi-site Facilities with Agent

Technology .....................................

M.K. Lim and H.K. Chan

Proposing an Environmental Excellence Self-Assessment Model . .

Peter Meulengracht Jensen, John Johansen,

Brian Vejrum Waehrens, and Md. Shewan-Ul-Alam

\section{Supply Networks and Supply Chain Management}

Method for Quality Appraisal in Supply Networks................

João Gilberto Mendes dos Reis and Pedro Luiz de Oliveira Costa Neto

Chinese SMEs' Sourcing Practices and Their Impact on Western

Suppliers

Matthias Wandfluh, Christian Schneider, and Paul Schönsleben

Game Theory Based Multi-attribute Negotiation between MA and

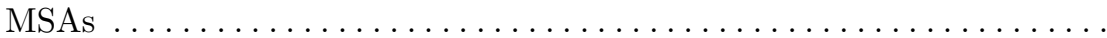

Fang Yu, Toshiya Kaihara, and Nobutada Fujii

Supplier Selection Criteria in Fractal Supply Network.............

Sameh M. Saad, Julian C. Aririguzo, and Terrence D. Perera

A Test-Bed System for Supply Chain Management Incorporating

Reverse Logistic

Shigeki Umeda

A Dyadic Study of Control in Buyer-Supplier Relationships ......... Anna Aminoff and Kari Tanskanen

A Fuzzy Decision Support System for Drawing Directions

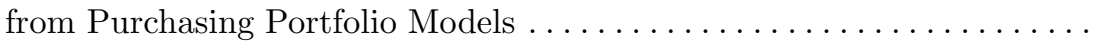
568

Davide Aloini, Riccardo Dulmin, and Valeria Mininno

A Mixed-Integer Linear Programming Model for Transportation Planning in the Full Truck Load Strategy to Supply Products with Unbalanced Demand in the Just in Time Context: A Case Study ....... . 576 Julien Maheut and Jose Pedro Garcia-Sabater

Improving the Application of Financial Measures in Supply Chain Management ....................................

Felix Friemann, Matthias Wandfluh, Paul Schönsleben, and Robert Alard 
Total Cost of Ownership for Supply Chain Management: A Case Study

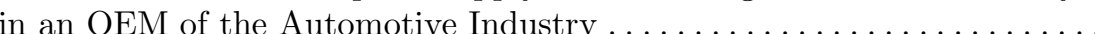

Paulo Afonso

Greening Manufacturing Supply Chains - Introducing Bio-based Products into Manufacturing Supply Chains . 600

David Sparling, Fred Pries, and Erin Cheney

Opportunistic and Dynamic Reconfiguration of Vehicle Routing Problem Controlled by the Intelligent Product . . . . . . . . . . . 608

Rodrigue Tchapnga Takoudjou, Jean-Christophe Deschamps, and Rémy Dupas

\section{Production Management, Operations and Logistics}

Tactical and Operational Issues in a Hybrid MTO-MTS Production Environment: The Case of Food Production ...................

Anita Romsdal, Emrah Arica, Jan Ola Strandhagen, and Heidi Carin Dreyer

A Note on the Simple Exponential Smooth Non-optimal Predictor, the Order-up-to Policy and How to Set a Proper Bullwhip Effect . . . . . . . . . Erland Hejn Nielsen

One-of-a-Kind Production (OKP) Planning and Control: An Empirical Framework for the Special Purpose Machines Industry . . . . . . . . . . . . Federico Adrodegari, Andrea Bacchetti, Alessandro Sicco, Fabiana Pirola, and Roberto Pinto

A Basic Study on Highly Distributed Production Scheduling . . . . . . . . . 638 Eiji Morinaga, Eiji Arai, and Hidefumi Wakamatsu

A Design of Experiments Approach to Investigating the Sensitivity of

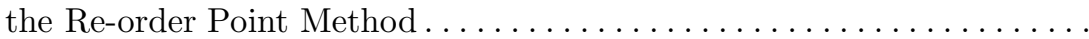
Peter Nielsen, Giovanni Davoli, Izabela Nielsen, and Niels Gorm Malý Rytter

Challenges of Measuring Revenue, Margin and Yield Optimization in

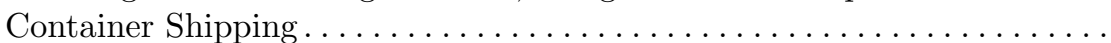
Albert Gardon, Peter Nielsen, and Niels Gorm Malý Rytter

Improving Port Terminal Operations through Information Sharing . . . . . 662 Peter Bjerg Olesen, Iskra Dukovska-Popovska, and Hans-Henrik Hvolby

Perishable Inventory Challenges. . . . . . . . . . . . . . . .

Cecilie M. Damgaard, Vivi T. Nguyen, Hans-Henrik Hvolby, and Kenn Steger-Jensen 
Assessing the Impact of Management Concerns in E-business

Requirements Planning in Manufacturing Organizations............

John Dilworth and Ashok Kochhar

Supporting the Design of a Management Accounting System of a Company Operating in the Gas Industry with Business Process

Modeling 686

Nikolaos A. Panayiotou and Ilias P. Tatsiopoulos

Base Stock Inventory Systems with Compound Poisson Demand: Case of Partial Lost Sales

M. Zied Babai, Ziad Jemai, and Yves Dallery

A Concept for Project Manufacturing Planning and Control for Engineer-to-Order Companies

Pavan Kumar Sriram, Erlend Alfnes, and Emrah Arica

Practical Considerations about Error Analysis for Discrete Event

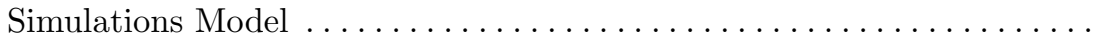

Giovanni Davoli, Peter Nielsen, Gabriele Pattarozzi, and Riccardo Melloni 